\title{
A FORMAÇÃO DO ESTADO BRASILEIRO A PARTIR DA LEITURA DE NORBERT ELIAS
}

\author{
David Antônio de Castro Netto (iD) 1
}

\section{Resumo}

O objetivo deste texto é apresentar algumas reflexões a partir dos resultados preliminares de uma pesquisa que tem por objetivo compreender a formação do Estado brasileiro a partir do programa teórico-metodológico do sociólogo Norbert Elias. A partir da proposta eliasiana, procuramos compreender de que maneira a violência tornou-se parte fundamental da formação do Estado brasileiro, sobretudo, a partir da constatação do uso racional, ou seja, a violência como estratégia de governo, marcando, assim, uma oposição ao movimento de restrição e concentração da violência que ocorria na Europa desde meados do século 16. Assim, ao contrário do que aponta Norbert Elias ao analisar a corte francesa, os processos de coação e autocoação, de repressão de impulsos, inerentes ao processo de complexificação das sociedades sofre mais restrições nas antigas colônias, na medida em que a violência não consegue ser monopolizada pelo Estado e os processos de distribuição de poder após a Proclamação da República sofrem constantes refluxos. Nossa conclusão apontará para algumas direções. Primeiro, destacamos que o processo de concentração e restrição da violência ocorre parcialmente já que o Estado não conseguirá monopolizar seu uso. Segundo esta formação social, baseada na violência, impede que se desenvolvam outros tipos de interrelações, baseadas na simbologia, por exemplo, que sejam suficientes para imposição de novos comportamentos, pautados em novos protocolos que procurem restringir a violência no cotidiano e/ou no espaço público.

Palavras-chave: Estado; Violência; Norbert Elias.

\section{THE FORMATION OF THE BRAZILIAN STATE FROM THE READING OF NORBERT ELIAS}

\section{Abstract}

The objective of this text is to present some reflections based on preliminary results of a research that aims to understand the formation of the Brazilian State from the theoretical-methodological program of the sociologist Norbert Elias. Based on the eliasian proposal, we seek to understand how violence has become a fundamental part of the formation of the Brazilian State, above all, from the observation of rational use, that is, violence as a government strategy, thus

${ }^{1}$ Doutor em História pelo Programa de Pós-Graduação em História da Universidade Federal do Paraná (UNIESPAR). Professor da Universidade Estadual do Paraná (UNESPAR) Campus de Paranavaí. 
marking an opposition to the movement of restriction and concentration of violence that occurred in Europe since the middle of the 16th century. Thus, contrary to what Norbert Elias points out when analyzing the French court, the processes of coercion and self-coercion, of repression of impulses, inherent to the process of complexification of societies suffers more restrictions in the former colonies, as the violence cannot be monopolized by the State and the processes of power distribution after the Proclamation of the Republic suffer constant refluxes. Our conclusion will point to some directions. First, we emphasize that the process of concentration and restriction of violence occurs partially since the State will not be able to monopolize its use. Second this social formation, based on violence, prevents the development of other types of interrelationships, based on symbology, for example, that are sufficient to impose new behaviors, based on new protocols that seek to restrict violence in daily life and / or in public place.

Keywords: State; Violence; Norbert Elias.

\section{Introdução}

Embora estejamos envolvidos numa atmosfera de supervalorização do indivíduo, que, por sua vez, desenvolve uma relação egocêntrica com o Estado e o restante da sociedade, não é possível compreendê-lo fora da sociedade na qual interage, da mesma maneira que não podemos compreender essa sociedade sem os sujeitos que a compõem, ou seja, necessitamos de uma compreensão interrelacional de sujeito-sociedade2 .

Quando observamos esta relação na longa duração, podemos notar as transformações pelas quais passou, apontando a forma pela qual interferiu na natureza do indivíduo e na forma como atua no contexto social. É aquilo que Elias $(1993 ; 2011 ; 2014)$ chamou de "psicogênese" e "sociogênese". A primeira, vinculada as modificações do comportamento humano e das estruturas de personalidade dos indivíduos e, a segunda, corresponde a uma teoria do desenvolvimento social, do Estado e das nações.

O sociólogo alemão toma como exemplo o caso da corte francesa (ELIAS, 2001). De acordo com sua análise, o processo de concentração do poder nas mãos do rei Luís XIV, o "Rei Sol", foi seguido pela centralização política e, especialmente, de quem estava autorizado a fazer uso legitimo da violência, primeiro o rei e, depois, o Estado.

A consolidação da corte francesa, foi, aos poucos, transformando o comportamento de um conjunto de indivíduos que tiveram que fazer a transição do guerreiro para o cortesão. As novas imposições sociais foram dialogando com as novas imposições pessoais. Em suma, os sujeitos passaram a sofrer

\footnotetext{
${ }^{2}$ Este texto apresenta alguns resultados de pesquisa, adicionando contribuições dos debates realizados no XVII Simpósio Internacional Processos Civilizadores: interdependências em processo, realizado entre os dias 17-20 de novembro de 2020 em Bogotá, Colômbia.
} 
processos de coação para exercer autocontrole sobre si e sobre seus impulsos, tendo em vista que o aumento da complexidade das relações sociais obrigatoriamente criava situações de dependência, que não podem ser mais resolvidas pelo uso da violência física.

A figura do rei absolutista e do Estado Nacional são importantes porque determinam a transição de uma sociedade guerreira, onde a violência fazia parte do jogo político, na medida em que nenhum controle central poderia ser feito, para uma sociedade cuja o centro emanador da violência seria apenas um. Como aponta Norbert Elias numa série de exemplos da transformação dos comportamentos (a mesa, no modo de vestir etc.) uma nova psique foi, aos poucos e com resistência, sendo construída até atingir a "maturidade" durante o reinado que precedeu a Revolução Francesa.

O flerte com a psicanálise do autor é notório. No encontro com os textos sociológicos de Sigmund Freud, Norbert Elias compreende que a formação do convívio social das pequenas comunidades até os Estados mais complexos, dependeu de um constante controle dos impulsos inerentes a existência humana.

Grosso modo, estas transformações reverberam no indivíduo e na sociedade da qual faz parte. O controle externo, sofrido na infância por diversas instâncias, procura moldar uma personalidade condizente com o convívio social desejado até que o indivíduo passa a exercer o autocontrole.

Não pretendemos avançar neste campo psicanalítico. Gostaríamos apenas de destacar que o próprio Freud, em "Totem e Tabu", reconheceu que a horda primitiva da qual a sociedade e os indivíduos evoluíram tem início a partir do ato impulsivo do assassinato do pai (aquele que tinha o controle do falo, da fala e das mulheres) e não de uma ação calculada, típica de sociedades mais complexas:

O primitivo não é inibido, o pensamento logo se converte em ato, nele o ato seria antes um substituto para o pensamento; por isso creio, sem reivindicar definitiva certeza na decisão, que no caso em discussão é lícito supormos que "no princípio foi o Ato" (FREUD, 2014, p. 244).

Por sua vez, Norbert Elias, entende que em sociedades guerreiras, os indivíduos tendem a viver de forma mais ativa e menos reflexiva, especialmente, porque os vínculos sociais são baseados na força e na coação física. Se tomamos estes pensamentos como fiadores (Freud e Elias) compreenderemos que a fase mais instintiva da vida humana está na infância e seu processo de controle e a conversão para o convívio social impõe-se como algo castrador.

O aspecto central que ressaltamos aqui é a forma como a violência se articula nestes processos. Ao analisar a feudalização, Elias (1993, p. 195) aponta: 
A compulsão por situações competitivas levou certo número de senhores feudais ao conflito, que o círculo dos competidores foi lentamente reduzido, que tal fato levou ao monopólio de um deles, e finalmente - em combinação com outros mecanismos de integração, como os processos cada vez mais intensos de formação de capital e diferenciação funcional - culminou na formação do Estado absolutista. Toda essa reorganização dos relacionamentos humanos se fez acompanhar de correspondentes mudanças nas maneiras, na estrutura da personalidade do homem, cujo resultado provisório é nossa forma de conduta e de sentimentos "civilizados".

$\mathrm{Na}$ medida em que este Estado se consolida, aumenta a cadeia de interdependências que os indivíduos estabelecem, já que o acesso a este Estado se torna cada vez menos regulado pelo uso da força e mais pela formalização dos costumes. O aumento da complexidade da teia social que surge na esteira da expansão da atuação destes Estados traz consigo novas funções sociais (os quadros que compõem a burocracia estatal, por exemplo) que são exercidas não por base em demonstrações de força, mas em diferenciações sociais que vão enquadrando os sujeitos na estrutura deste mesmo Estado.

Evidentemente, isto não inibe e nem poderia inibir as rupturas revolucionárias. Contudo, elas são explicáveis não como retrocessos civilizacionais, mas como formas de reorganização do poder no interior desta mesma estrutura social que, como sugere Norbert Elias, está sempre num movimento dinâmico, naquilo que o autor chamou de equilíbrio instável de poder. Em suma:

De modo geral, a direção em que o comportamento e a constituição afetiva das pessoas mudam, quando a estrutura dos relacionamentos humanos é transformada da maneira acima descrita, é a seguinte: as sociedades sem um monopólio estável da força são sempre aquelas em que a divisão de funções é relativamente pequena, e relativamente curtas as cadeias de ações que ligam os indivíduos entre si. Reciprocamente, as sociedades com monopólios mais estáveis das forças, que sempre começam encarnadas numa grande corte de príncipes ou reis, são aquelas em que a divisão das funções está mais ou menos avançada, nas quais as cadeias de ações que ligam os indivíduos são mais longas e maior a dependência funcional entre as pessoas. Nelas o indivíduo é protegido principalmente contra ataques súbitos, contra a irrupção de violência física em sua vida. Mas, ao mesmo tempo, é forçado a reprimir em si mesmo qualquer impulso emocional para atacar fisicamente outra pessoa (ELIAS, 1993, p. 198).

Este processo não pode ser desvinculado das modificações psíquicas dos indivíduos, ou seja, são transformações que ocorrem concomitantemente. A maior especialização das sociedades torna mais complexa a teia de interdependências e o indivíduo precisa, cada vez mais, regular seu comportamento. Ao fim, a existência de dois monopólios (força e tributação) propicia uma solidez, forjando estruturas que conseguem atuar no longo prazo. 


\section{Estado e Violência no Brasil}

Compreender a formação do Estado brasileiro é tarefa complexa, sobretudo porque não pode ser entendido como mera replicação do modelo político europeu, tendo em vista muitas especificidades, tanto do Brasil, quanto da Europa. A primeira delas, e bastante definidora dos marcos do Estado nacional, não apenas no Brasil, mas em toda América é o impacto da colonização nas sociedades americanas pré-coloniais. Sobre este processo, Norbert Elias (1997) aponta:

Um dos mais radicais processos de informalização desse tipo foi a destruição dos rituais que davam significado à vida e sustentavam modelos de vida coletiva entre os povos mais simples, no processo de colonização e no trabalho missionário por europeus. (...) Um dos mais extremos exemplos da desvalorização de um código que fornece significado e orientação a um grupo em ligação com a perda de poder do seu grupo-portador é a eliminação as classes superiores na América Central e do Sul, no decorrer da colonização e imposição do cristianismo pelos espanhóis e portugueses. É verdade que nesses casos o antigo establishment foi substituído por um novo, mas o código de regras pelo qual o novo establishment regeu sua vida foi, no começo, incompreensível para os povos conquistados. Dificilmente poderia compensar a perda de significado. (...) Merece um exame mais cuidadoso, o que significa para os povos envolvidos experimentar a relativamente rápida destruição dos modos de vida que Ihes deram significado e valor, e ter novos modos e um diferente código violentamente enxertados neles por um novo establishment. Expressões como "conversão ao cristianismo" pouco ajudam: elas representam o ponto de vista dos conquistadores, não dos conquistados. (ELIAS, 1997, p. 77).

Este processo, como salientamos, promove uma inversão no que diz respeito à violência. Na Europa Central ela foi sendo banida da esfera pública e seu controle e exercício assumido por uma instituição centralizada que adquiriu estabilidade (Estado) e dialogou com uma transformação dos comportamentos, que agora precisavam ser mediados por gestos ou palavras.

No caso brasileiro, como sugere Gebara (2012, p. 2), a violência foi utilizada racionalmente como forma de organização social. Primeiro, na dominação dos nativos americanos e na manutenção da escravidão das populações africanas, informando para o conjunto social uma diferenciação de cor e raça que ganhou dinâmica própria, ou seja, se sedimentou no corpo no social para além do período colonial. Segundo, como pedra angular de organização do processo produtivo, escravidão e monocultura ${ }^{3}$. A expansão da fronteira agrícola, ao contrário da "Marcha para o Oeste", não foi orientada para o povoamento do interior, mas provocou o despovoamento, na medida em que

${ }^{3} \mathrm{~A}$ historiografia contribuiu para esta percepção desde a obra de Caio Prado Jr. Com razão, o autor afirma que estas eram as duas únicas instituições que funcionavam regularmente. 
deslocou pessoas para as diversas formas de trabalho compulsório ou escravo, predominantemente, no litoral.

Ao lado da organização da escravidão de africanos e outras formas de superexploração do trabalho da população nativa, a violência torna-se componente estrutural e estruturante. Primeiro, existindo sem o monopólio do Estado, já que esta figura era incipiente até, pelo menos, a descoberta de outro e prata. Segundo, além da violência, as populações originárias e africanos escravizados existiam, como apontou N. Elias, numa estrutura de poder que não Ihes diz respeito e sendo constantemente alvo de uma dupla violência, do Estado e das organizações que concorriam com ele (milícias, capangas, coronéis etc.).

Como sustenta Gebara (2012):

Esta faceta assumida pelo processo de integração euro americano, implica em reconsiderar a formulação clássica da questão da violência, tal como Elias a colocou. A violência que se verifica no caso da formação do Estado no Brasil, não pode ser compreendida apenas na dimensão de um processo civilizacional, onde o controle das emoções construiria um 'habitus', mais ou menos como se verificou na Europa, na medida em que os guerreiros foram se transformando em cortesões. No caso brasileiro, a violência e, ou, a tolerância foram racionalmente utilizadas, quer para dominar os índios, quer, para conquistar o território, mais especificamente a fronteira agrária em expansão. Neste caso, a violência é um componente estrutural da política estatal, as consequências deste fato são bastante evidentes na História do sistema policial brasileiro. (GEBARA, 2012, p. 07).

Este é um elemento que chamamos atenção, o impacto dos 388 anos de escravidão na formação da psicogênese e sociogênese das elites brasileiras. Novamente, vale a pena a comparação. Enquanto a Europa avançava (ainda que em ritmos diferentes) na consolidação das interdependências e imposição de novas formas de comportamento, que passam a ser ensinados por meio dos manuais de boa conduta e/ou de comportamento, estas cadeias de relações passavam a ser regidas pela simbologia e não pela violência.

No caso brasileiro, e da colonização em geral ${ }^{4}$, este processo não ocorre. Primeiro, antes da emancipação política de Portugal. Embora a relação senhor $x$ escravo obscureça, é possível notar um conjunto de estratos sociais que estão entre os dois extremos 5 , numa relação de dependência que variava de acordo com os ciclos econômicos. Estas interdependências não eram mediadas pela simbologia da corte ou pela presença estatal, mas pelo exercício direto das

${ }^{4}$ Como aponta, Achille Mbembe (MBEMBE, 2018), desde meados do século 16, ou seja, com a expansão da colonização na América, Ásia e África, a violência passa a ser regulada na Europa enquanto tinha o uso racionalizado nas colônias, criando uma política de gestão da morte, a necropolítica.

${ }^{5}$ Este é o caso do amplo estudo de Ferlini (2002), que aponta a diversificação da ocupação dos africanos transformados em escravos durante o período colonial. 
diversas formas de violência física e por uma simbologia que mantenha formas de violência no cotidiano.

Como resultado, um corpo político minoritário, mas com potencial considerável de retenção de poder, teve seu traço de personalidade forjado pelo uso explícito da violência para com aquele considerado inferior e não pelo paulatino banimento desta violência da esfera pública. Este traço é confirmado pela ausência de discussão sobre o fim da escravidão durante as revoltas coloniais, à exceção da Revolta dos Malês. Durante o processo de transição da escravidão para o trabalho livre, escravocratas fizeram uso do trabalho escravo até quando foi possível. De acordo com Carvalho (1990), mesmo com a possibilidade de serem ressarcidos pelo Estado, os proprietários de escravos, optaram por usar o braço escravo até os 21 anos, como regulava a lei de 1871 .

Esta anotação pode ser seguida por um conjunto considerável de demonstrações empíricas. Ainda no período colonial, conforme destaca Caio Prado Jr. (1953), os escravos eram, seguindo os preceitos das Ordenações Manuelinas, mantidos na condição de "bestas".

Embora as cartas constitucionais fizessem uso de expressões "a lei será igual para todos, quer proteja, quer castigue, e recompensará em proporção dos merecimentos de cada um." (BRASIL, 1824) ou ainda proibição de penas consideradas cruéis, "Art. 179. XIX. Desde já ficam abolidos os açoites, a tortura, a marca de ferro quente, e todas as mais penas crueis." (BRASIL, 1824), em nenhum momento procura inserir essas populações no cenário político.

Se, por um lado, as cartas constitucionais procuram aglutinar elementos liberais importados da França ou da Inglaterra, como a liberdade de expressão e de reunião, o código penal demonstra o caráter explícito para quem a violência seria destinada. De acordo com o código criminal de 1830:

\section{CAPITULO IV INSURREIÇÃO:}

Art. 113. Julgar-se-ha commettido este crime, retinindo-se vinte ou mais escravos para haverem a liberdade por meio da força.

Penas - Aos cabeças - de morte no gráo maximo; de galés perpetuas no médio; e por quinze annos no minimo; - aos mais açoutes.

Art. 115. Ajudar, excitar, ou aconselhar escravos á insurgir-se, fornecendo-lhes armas, munições, ou outros meios para o mesmo fim.

Penas - de prisão com trabalho por vinte annos no gráo maximo; por doze no médio; e por oito no minimo (BRASIL, 1830).

Até os anos 1930, um projeto claro de nação ainda não existia. Contudo, isto não impediu tentativas deliberadas pelo Estado (imperial ou republicano) de qualificar o "povo brasileiro". Aqui, o nó da "democracia racial" ganha relevância não apenas por fornecer esse (falso) material, mas por acabar legitimando a continuidade de uma ação individual. 
A ideia de "conciliação" ou de "integração" já existia nos círculos intelectuais brasileiros desde o ensaio do alemão Phillip Von Martius sobre como se deve escrever a história do Brasil. Essa trajetória foi reforçada em diversos campos, na academia, no Instituto Histórico e Geográfico Brasileiro (IHGB) e na vertente romântica da literatura nacional.

Como destaca Carvalho (1990), a Proclamação da República foi seguida por inúmeras tentativas de legitimar o novo sistema, de encontrar símbolos e heróis que inspirassem a população, até então deslocada do movimento, a incorporar a simbologia republicana. Tal busca tornou-se particularmente difícil já que a transição política envolveu número reduzido de pessoas e ainda existem dúvidas sobre as intenções republicanas de seus protagonistas, especialmente Deodoro da Fonseca.

A escolha recaiu sobre Tiradentes. A opção estava vinculada à possiblidade de galvanizar uma revolta cuja violência não se realizou, portanto, não houve derramamento de sangue dos "inimigos" que eram os mesmos que estavam no poder ${ }^{6}$. Outro aspecto era a possibilidade de apelo à simbologia, o que faria toda diferença numa sociedade analfabeta. Neste caso uma simbologia cristã, na medida em que sua iconografia o aproximou da imagem ocidentalizada do messias. De acordo com Carvalho (1990, p. 68), Tiradentes:

Foi vítima não só do governo português e de seus representantes, mas até mesmo de seus amigos. Vítima da traição de Joaquim Silvério, amigo pessoal, o novo Judas. E vítima também dos outros companheiros da conspiração, que, como novos Pedros se acovardaram, procuraram lançar sobre ele toda culpa. Culpa que ele assumiu de boa vontade. Congratulou-se com os companheiros quando foi comunicada a suspensão da sentença de morte, satisfeito por ir sozinho ao cadafalso. Explicitamente, como Cristo, a quem quis imitar na nudez e no perdão ao carrasco, incorporou as culpas, as dores, os sonhos dos companheiros e dos compatriotas. Operava pelo sacrifício, no domínio místico, a salvação que não pudera operar no domínio cívico.

Essa avaliação é pertinente na medida em que, como salientou (ELIAS, 1997), as novas estruturas de poder colonial não produziram significado para as populações colonizadas. Tais continuidades impediram transformações e o aumento das interdependências estabelecidas entre os sujeitos. Sendo apenas pontuais, portanto, não conseguem impor coação suficiente para que indivíduos recalquem seus comportamentos.

Desta forma, a formação do Estado brasileiro se configura a partir da manutenção de estruturas de poder ou, no máximo, com poucas alterações. Mantém, ainda, as formas simbólicas de organização, cujo traço da cor e da raça se mantiveram em primeiro plano. Não se expande a partir de sua

\footnotetext{
"Vale lembrar que Deodoro, o "proclamador da república" era neto de D. Maria I, contra quem
} haviam se rebelado os inconfidentes. 
horientalização, mas, continua privatizado, como destacou Sérgio Buarque de Holanda (2016), tornando-se instrumento do uso familiar.

As alterações políticas, sociais e econômicas, que começam a ocorrer a partir dos anos 1920 se, por um lado, ofereceram alternativa para o modelo econômico na direção de intensificar a industrialização brasileira, não conseguiu superar o modelo sociocultural. A imposição de um novo ciclo econômico desafiava as elites agrárias nordestinas, colocando-as em desvantagens frente à nova elite cafeicultora e industrial do sudeste brasileiro.

O dilema do "papel histórico" destas elites foi resolvido por Gilberto Freyre. Ao analisar o cotidiano da escravidão brasileira, intencionalmente ou não, constrói a ideia de que a violência do modelo econômico escravista não era uma questão de raça, mas de economia. Portanto, a herança a ser preservada daquele período foi a cultura produzida da relação entre a Casa Grande e a Senzala. As intepretações da obra de G. Freyre apontam para uma espécie de síntese do Brasil a partir daquela dinâmica. Assim, do ponto de vista deste texto, as leituras a partir da obra de Gilberto Freyre permitem a naturalização da violência ou, pelo menos, da violência enquanto forma de comportamento social e desmonta a ideia da violência racial e desloca o problema para a questão do modelo econômico (escravismo).

Um dado empírico interessante a ser notado são os manuais de boas maneiras. Os primeiros começam a circular no Brasil em meados do século 19 (1845), contudo, outros já circulavam, voltados para a agricultura e no trato com a escravidão (1830). O que é possível notar é a concorrência. De um lado, manuais de boa conduta procuravam internalizar nos diversos sujeitos (homens, mulheres e crianças) e instituições (escola, família, igreja) uma formalização dos comportamentos e um aumento do autocontrole dos instintos e desejos.

Por outro, um conjunto de textos, como o Manual do Agricultor Brasileiro (1839), procuravam ensinar aos proprietários de terras as melhores maneiras de manter seus escravos o maior tempo possível no trabalho. O objetivo era dosar violência e existência dos sujeitos, em suma, não proporcionavam autocontrole, mas uso controlado da violência.

Como ressalta Malerba (2000), a elite portuguesa utilizou a etiqueta como maneira de diferenciação social e as elites brasileiras passaram por um processo de tentativa de europeização dos costumes através da imitação que foi sendo plasmada sob a continuidade da tradição indígena e africana que existiam.

O que procuramos observar neste texto é em que medida tais imitações previstas por Norbert Elias ${ }^{7}$, foram introjetadas no comportamento individual e coletivo destas elites. Tal questionamento é pertinente na medida em que este autocontrole se torna útil quando pensamos no espaço público. Como demonstrou Sérgio Buarque de Holanda (2016), o "homem cordial" é produto desta dificuldade em conseguir exercer controle sob o seu comportamento. Isto

\footnotetext{
${ }^{7}$ As classes inferiores procuram imitar os costumes das classes superiores, como forma de diminuir as diferenciações sociais trazidas pela etiqueta. Estas por sua vez, refinam novamente seu comportamento para que não percam o traço de distinção que a etiqueta oferecia.
} 
se revela nas diversas esferas, especialmente, nas ocasiões consideradas excessivamente formais e na forma como o espaço público é privatizado sob a régua dos costumes familiares.

A consolidação da estrutura escolar, ainda que insuficiente, mas cada vez mais robusta, procurava educar as crianças e disciplinar seus comportamentos sob diversas formas, tornando os indivíduos capazes de controlar seus impulsos e emoções. Foi o momento de maior circulação de manuais de boas maneiras, alguns chegando a mais de dez edições ${ }^{8}$. As campanhas em busca da "civilização dos humildes" foram contínuas durante toda a República, ainda que sob diversas formas. Suas aparições mais explícitas talvez tenham sido durante os anos da ditadura civil-militar, quando figuras como Sujismundo e Sujismundinho aparecem para ensinar jovens e adultos boas maneiras de comportamento.

A teoria eliasiana de poder sugere que este elemento não pode ser exercido unilateralmente, ou seja, é sempre interrelacional. Na medida em que as sociedades se tornam mais complexas e a rede de interdependências aumenta, também aumenta a capacidade organizativa e de retenção de poder de grupos considerados minoritários (menos potencial de retenção de poder) e que, tendo em vista a natureza da distribuição de poder (especialmente em estados democráticos) conseguem pressionar o centro e ter algumas demandas atendidas.

De acordo com Elias (2014) e Rezende (2012) são os processos de democratização que permitem as oscilações na balança de poder em favor de indivíduos e grupos. Ainda de acordo com os autores, tais processos ampliamse na medida em que aumentam consideravelmente 0 nível de interdependências dos sujeitos a partir da complexificação das sociedades industriais. Contudo, a expansão e a consolidação destes processos tiveram movimento variante e determinado pelas condições que cada conjunto social permitiu. Porém, é importante destacar:

O processo de democratização, segundo Elias, somente é possível desde que se forme, nas pessoas, uma disposição para agir de modo a não se temer o deslocamento e a distribuição do poder entre aqueles estratos que vão ganhando as condições para adentrar a arena política e reivindicar posições de poder. Por isso, para ele, a construção da democracia é um processo de transformação global que envolve mudanças na sociedade como um todo e na estrutura de personalidade dos indivíduos (REZEDE, 2012, p. 355).

\footnotetext{
${ }^{8}$ A virada do século 19 para o 20 ampliam a circulação destes manuais. Como aponta Rocha (2018), são alguns exemplos: Novo Manual do bom-tom (1900), de Luís Verardi; Entretenimentos sobre os deveres da civilidade colecionados para o uso da puerícia brasileira de ambos os sexos (1875), Guilherme de Azambuja Neves; Novos de civilidade e higiene corporal para o uso das crianças no lar e na escolas primárias (1918) do Clérigo José Sotero de Sousa e Livro das Donas e donzelas (1906) e Maternidade (1925), ambos de Julia Lopes de Almeida; Pequeno manual de civilidade para uso da mocidade (1932), o autor não identificado; Boas maneiras, manual de civilidade (1936), de Carmem D'Avila.
} 
Ou seja, estes deslocamentos significaram a modificação da condição política de estratos sociais que antes não eram reconhecidos. Este processo é observável, como aponta Elias (2014), pela diminuição da diferença entre governantes e governados, traduzida na criação de cartas constitucionais, na regulação dos governos pela lei, substituição, nos cargos do estado, de membros das elites por membros de partidos de massa, concursos públicos, a retirada de direitos hereditários etc.

Claro é, como aponta Rezende (2012), que N. Elias não está sugerindo a equalização do poder e, muito menos, que os processos de ampliação da democracia estão numa escala ascendente evolutiva, mas, destaca que é possível constatar instituições de médio/longo prazo que permitem aos governados estabelecer formas de controle avançados sobre aqueles que os governam.

A retomada histórica para tempos coloniais brasileiros revela aqui sua função. Quando recuperamos os conceitos de psicogênese e sociogênese se faz fundamental entender como comportamentos coletivos e individuais são forjados na longa duração. N. Elias está observando uma trajetória de mudanças comportamentais e individuais que tenderam à formalização dos costumes. Aqui, observamos uma trajetória que tendeu mais a permanência do que alterações (ainda que tenham existido). Isto significa dizer que, se o processo de democratização e distribuição do poder depende do reconhecimento de outros estratos sociais, pautados, grosso modo, pelo aumento das interdependências, quando colocamos o caso brasileiro em tela é necessário apontar como este processo de médio-longo prazo de diminuição dos contrastes e da diferença de poder foi bloqueado.

Ressaltamos, portanto, a maior potencialidade destas permanências, quando entendemos o espaço que ocupam no cotidiano político-social brasileiro. Como observou Gebara (2012), a violência tornou-se instrumento de ação do Estado. Isto é pertinente, já que mesmo quando este Estado procura atender demandas populares (a legislação trabalhista de Vargas, por exemplo) o faz, tendo como garantia de execução da sua política, instrumentos violentos, como é possível notar numa rápida análise da Constituição de 1937.

Estes avanços autoritários confirmam a hipótese de que o Estado, seja como for, fara uso do expediente da violência na execução de suas políticas. Existem inúmeros problemas nessa afirmação que a própria historiografia sobre o tema avança consideravelmente (medo, abandono social etc.), neste caso, do ponto de vista individual, ao lado do medo do Estado, especialmente para setores que se encontram numa posição fragilizada, podemos encontrar a manutenção da lógica da violência e a confusão constante entre autoridade e autoritarismo. Medo e obediência.

Como nenhuma sociedade é estática, as diferenças de poder também não o são. Mas, as saídas autoritárias comuns na história política do Brasil, revelam que os limites da nossa democracia são os limites impostos por um conjunto de indivíduos que resiste das diversas formas às transformações. 
Consideramos o caso da ditadura militar de 1964 como um exemplo singular dessa afirmação. Embora existam diversas correntes interpretativas ${ }^{9}$, é possível se aproximar da ideia proposta por Caio Navarro de Toledo (2004), quando sugere que a partir da década 1950 o Brasil começou a discutir projetos nacionais.

Este momento de expansão da luta política para sindicatos (urbanos e rurais), ligas camponesas que buscavam maior acesso à terra, o movimento estudantil, setores organizados da classe média e do movimento negro (desde pelo menos os anos 1930 com a Frente Negra Brasileira) ao convergirem procuram realocar-se não apenas na estrutura do Estado, mas individualmente, procuram impor novos comportamentos.

Todas as tentativas foram frustradas por uma organização extensa de instituições, partidos políticos, lideranças civis e militares que procuravam colocar-se em defesa do "verdadeiro Brasil". O sucesso do movimento (o golpe de 1964) demonstra que estes grupos dispunham de uma capacidade organizativa para defender na esfera pública, sua atuação na esfera privada.

Num caso específico, o das "Marchas com Deus pela Família e Liberdade" é possível notar um conjunto heterogêneo de forças. Isto dá a medida do potencial intraclasse que o apelo teve (foram 500 mil pessoas em São Paulo e outras milhares no Rio de Janeiro, para citar apenas os exemplos mais conhecidos).

A trajetória da ditadura militar ${ }^{10}$ e sua transição para a democracia também demonstrou outra tradição do comportamento individual e político nacional, a conciliação, especialmente no caso da Lei da Anistia (1979). A chamada conciliação pelo alto evita que outra forma de entender a violência seja compreendida, ou seja, o uso da violência contra aqueles que a transformaram em política de Estado. Por mais que houvesse pressão dos movimentos socais organizados em diversas frentes, é possível sugerir que o encerramento da ditadura foi menos longo do que provavelmente planejaram seus idealizadores, mas, outros elementos foram seguidos à risca. Como sugere Fico (2012):

Assim, temos aí também uma história incômoda, marcada pela frustração, mas que muitas vezes temos ocultado sob o manto de uma memória confortável, que erigiu como prevalecente o discurso da pressão que a resistência democrática teria sido capaz de exercer naqueles onze anos, mas que não vemos, retrospectivamente, em sua efetividade, já que a abertura foi conduzida tal e qual os militares a planejaram. (FICO 2012, p. 30).

Desta forma, entendemos, de acordo com Kehl (2010), que a violência se tornou um sintoma social na medida em que o que se passou foi um constante

\footnotetext{
9 Para uma revisão da bibliografia sobre a ditadura militar, indicamos o trabalho de Fico (2017).

10 Não queremos aqui nos alongar no debate sobre a ditadura militar, gostaríamos apenas de ressaltar os aspectos que são relevantes para este texto. Sobre a ditadura, indicamos o trabalho de Alves (2005).
} 
silenciamento adicionado ao ressentimento de traumas sociais significativos que foram ultrapassados com base em acordos que relegam setores sociais mais atingidos (pessoas escravizadas, militantes políticos, indígenas etc.) a colocarem-se lado a lado com àqueles que lhes perpetram a violência.

Nesse sentido, a questão não é apenas a tradição brasileira da conciliação, mas de evitar que estruturas estatais violentas se perpetuem, informando à estratos específicos da população que é permitido praticar tais atos já que seus julgamentos serão ou silenciados ou marginalizados na memória social.

Tais estruturas acabam por informar traços de personalidade que também são definidos por meio do uso da violência. Os dados sobre as mortes no Brasil são assustadores em todos os sentidos. Os dados do Atlas da Violência, publicado pelo IPEA em 2020 informam: feminicídios, em 2018 foram 4.519 mulheres assassinadas, o que significa um assassinato a cada duas horas, 4,3 por 100 mil. Entre 2008 e 2018, representou aumento de 4.2\%, crimes como agressão física ( 1 a cada 2 minutos) e estupro ( 1 a cada 8 minutos). Os crimes relacionados a homofobia somaram 224 assassinatos, segundo o relatório do Observatório de Mortes Violentas de LGBTQIA+, publicados em 2021, assim como a manutenção da estrutura penal do Estado brasileiro que volta seus canhões para o estrato social negro, pobre e jovem. Os dados do Anuário Brasileiro de Segurança Pública, promovido pelo Fórum Brasileiro de Segurança Pública (FBSP, 2020) informam que em 2019 havia 718.077 mil presos homens e 37.197 mil mulheres, totalizando 755.274, um aumento de 224\% entre 2011 e 2020. Deste total, 66.7\% são negros, em 2005 representavam $58.4 \%$. Além do assustador número de assassinatos que, em 2020 somaram 43.892 mortes.

\section{Considerações finais}

Neste artigo apresentamos as primeiras reflexões sobre as possibilidades de aplicação da teoria eliasiana para a compreensão dos processos históricos de formação do Estado e do habitus dos indivíduos fora da realidade europeia, sob a qual se debruçou o autor.

Como eixo central, procuramos apontar de que maneira a violência exerceu duplo papel. Primeiro, no controle e na forma da construção de diversas estruturas do Estado, ou seja, o uso racional da violência, inerente ao processo de colonização (sustentado pela lógica do trabalho escravo em suas diversas formas). Segundo, como não houve banimento suficiente da violência da esfera pública, seu uso ajudou a manter as estruturas individuais pouco alteradas.

O uso da violência está associado ao processo de informalização ao qual foram submetidas as populações ameríndias que, no longo prazo, destruiu as formas de sociabilidade que Ihes davam sentido, sendo substituídas por formas eurocentradas de cultura, sociedade e religião. Tal imposição, contudo, não foi suficiente para produzir uma relação de sentido e/ou aproximação entre Estado - Nação - individuo. Em suma, de diversas formas e intensidade, o estado se mantém estranho ao corpo de indivíduos, que muitas vezes, só conseguem 
ascender à condição de cidadão e exercer a cidadania quando esta relação é mediada pelo ingrediente privado (o apadrinhamento, por exemplo).

Por fim, salientamos que, aqui, não descartamos a presença constante da resistência de toda a sorte de revolta, rebeliões, motins e movimentos sociais. Todos eles são parte importante do processo de expansão dos direitos fundamentais que, pouco a pouco, vão garantindo condições melhores de existência para setores considerados vulneráveis da população. Contudo, aqui, procuramos apresentar reflexões mais gerais sob a formação Estado, questões como essas serão abordadas em trabalhos futuros, à medida que a pesquisa avance e novos documentos sejam agregados.

\section{REFERÊNCIAS}

ALVES, Maria Helena. Estado e oposição no Brasil (1964 - 1984). 1. ed. Bauru: Edusc, 2005.

ANSART, Pierre. Ideologias, conflitos e poder. 1. ed. Rio de Janeiro: Zahar Editores, v. 1, 1977.

BRASIL. Constituição Federal. 1824.

BRASIL. Código criminal do Império do Brazil, 1830.

CARVALHO, José Murilo. Os bestializados: O Rio de Janeiro e a república que não foi. São Paulo: Companhia das Letras, 1987.

CARVALHO, José Murilo. A formação das almas: o imaginário da República no Brasil. 1. ed. São Paulo: Companhia das letras, 1990.

CARVALHO, José Murilo. A construção da ordem e o teatro das sombras. Rio de Janeiro: Civilização Brasileira, 2003.

CARVALHO, José Murilo. A sociedade dos indivíduos. Rio de Janeiro: Zahar, 1994.

CARVALHO, José Murilo. Os alemães: a luta pelo poder e a evolução do habitus nos séculos XIX e XX. 1. ed. Rio de Janeiro: Zahar, 1997.

CARVALHO, José Murilo. A sociedade de corte: investigação sobre a sociologia da realeza e da aristocracia de corte. Rio de Janeiro: Zahar, 2001.

CARVALHO, José Murilo. O processo civilizador. Vol. 01: Uma história dos costumes. Rio de Janeiro: Zahar, 2011.

CARVALHO, José Murilo. Introdução a sociologia. Lisboa: Edições 70, 2014. 
ELIAS, Norbert. O processo civilizador. Vol. 02: Formação do Estttado e civilização. Rio de Janeiro: Zahar, 1993.

FERLINI, Vera Lúcia Amaral. Pobres do açúcar: estrutura produtiva e relações de poder no nordeste colonial. São Paulo: Hucitec/Edusp/Imprensa Oficial, 2002.

FICO, Carlos. Brasil: a transição inconclusa. In: ARAÚjo, Maria Paula; FICO, Carlos; GRIN, Mônica. Violência na história: memória, trauma e reparação.

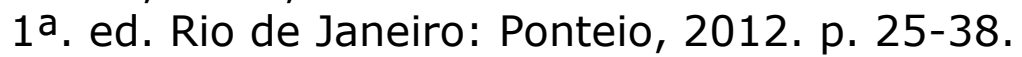

FICO, Carlos. Ditadura militar brasileira: aproximações teóricas e historiográficas. Revista Tempo e Argumento, Rio de Janeiro, n. 09, p. 0574, maio, 2017.

FBSP, Fórum Brasileiro de Segurança Pública. Anuário Brasileiro de Segurança Pública, 2020. Disponível em https://forumseguranca.org.br/wpcontent/uploads/2020/10/anuario-14-2020-v1-interativo.pdf Acesso em: 23 jun. 2021.

FREUD, Sigmund. Obras completas, volume 17: inibição, sintoma e angústia, o futuro de uma ilusão e outros textos (1926-1929). 1. ed. São Paulo: Companhia das Letras, v. 17, 2014.

GEBARA, Ademir. Discutindo o processo civilizador brasileiro. XIV Simpósio Nacional Processos Civilizadores: Civilidade, fronteira e diversidade; IV Seminário do Grupo de Pesquisa, Educação e Processo Civilizador. Anais..., Dourados: UFGD, 2012, p. 01-11.

GEBARA, Ademir. Processos Civilizadores na América Latina: Possibilidades e Problemas. Dourados: [s.n.]. 2012. p. 1 - 10.

GEBARA, Ademir. Civilización y Formación de Naciones en América: El caso brasileño. XV Congresso Internacional Procesos civilizatorios - UNAM. Anais..., Cidade do México: UNAM, 2014. p. 01-19.

FREYRE, Gilberto. Casa-Grande \& Senzala: formação da família brasileira sob o regime da economia patriarcal. $51^{\text {a }}$ edição. São Paulo: Global Editora, 2016.

HOLANDA, Sérgio Buarque. Raízes do Brasil. São Paulo: Companhia das Letras, 2016.

JÚNIOR, Caio Prado. Evolução política do Brasil e outros estudos. 4. ed. São Paulo: Editora Brasiliense, 1953. 
KEHL, Maria Rita. Tortura e sintoma social. In: TELES, Edson; SAFATLE, Vladimir. O que resta da ditadura: a exceção brasileira. 1. ed. São Paulo: Boitempo, 2010, p. 123-132.

MARTIUS, Carl Friedrich Phillip von. "Como se deve escrever a história do Brasil". Revista do Instituto Histórico e Geográfico Brasileiro, v. 6, n. 24, p. 389-411, jan. 1845.

MBEMBE, Achille. Necropolítica. [S.I.]: N-1 Edições, 2018.

REZENDE, Maria José. A democracia como transformação global da sociedade e dos indivíduos em Norbert Elias. Polis. Revista de la Universidad Bolivariana, Chile, v. 11, n. 32, p. 351-375, 2012.

ROCHA, Rita de Cássia Luiz. Manuais de civilidade e educação: "a conduta da juventude feminina" de Sophie Christ. 2018. $161 \mathrm{f}$. Tese (Doutorado em Educação) - Universidade Metodista de Piracicaba/UNIMEP, Piracicaba, 2018.

SAFATLE, Vladimir. Identitarismo Branco. El Pais, São Paulo, 04 Setembro 2020.

TAUNAY, Carlos Augusto. Manual do agricultor brasileiro. Rio de Janeiro: Tipografia Imperial, 1839.

TOLEDO, Caio Navarro. 1964: o golpe contra as reformas de base e a democracia. Revista Brasileira de História, v. 24, n. 47, p. 13-28. 2004.

Recebido em: 15 de março de 2021. Aceito em: 24 de junho de 2021. Publicado em: 30 de junho de 2021. 